\title{
Degradation and transfer of polyacrylamide based flocculent in sludge and industrial and natural waters
}

\author{
J. Guzzo • A. G. Guezennec
}

Received: 6 August 2014 / Accepted: 21 August 2014 / Published online: 12 September 2014

(C) Springer-Verlag Berlin Heidelberg 2014

Flocculants are widely used in numerous industrial domains (food-processing industry, mineral industries, chemical industries, water purification, wastewater treatment) to improve the solid/liquid separation in water-containing fine particles. Thanks to the addition of flocculants, particles gather together and form flocs that improve the materials aggregation and wastewater clarification. At the molecular level, flocculants can be mineral polymers or natural organic polymers, but synthetic organic polymers constitute the main flocculants. Generally, they are anionic polyacrylamides produced by polymerisation of acrylamide and the anionic co-monomer, the sodium acrylate. Monomers are only partially eliminated during polyacrylamide preparation and remain at the state of tracks in the end product. According to Smith et al. (1996), the residual content in monomers varies between 0.05 and $5 \%$. Sodium acrylate presents no harmfulness like the polyacrylamide (Stephens, 1991). However, as the acrylamide is considered as a carcinogenic molecule, mutagen and reprotoxic (Molak, 1991), all polyacrylamides (PAMs) used within the European Union are required to contain less than $0.1 \%(w / w)$ of residual acrylamide (AMD) (European Parliament 1999) unless they are classified and labelled as a category 2 carcinogen (European Parliament 2006). More stringent thresholds

Responsible editor: Philippe Garrigues

\section{J. Guzzo}

Jules Guyot Institut, University of Burgundy,

Claude Ladrey Street, 21000 Dijon, France

e-mail: jean.guzzo@u-bourgogne.fr

J. Guzzo

e-mail: jean.guzzo@nexidia.fr

A. G. Guezennec $(\bowtie)$

BRGM - Water, Environment \& Ecotechnologies Division,

3, av. Claude Guillemin, BP 36009, 45060 Orléans Cedex 2, France

e-mail: a.guezennec@brgm.fr are also set depending on additional regulations covering specific uses like, for example, when PAM-based flocculants are used for the treatment of drinking water (no more than $0.05 \%$ of residual AMD).

The potential risks on environment and health are thus linked to the spreading of acrylamide and polyacrylamide degradation products in the natural environment. Two levels of spreading have to be considered:

- The water: about $95 \%$ of the polymers adsorb on the particles during flocculation stage. Five percent of the polymer as well as all the residual monomers remain dissolved in the water and may spread in surface and ground waters. At the end of the water clarification process, the lagoon as well as the pond used for storing the clarified waters are opened systems subjected to constant exchanges with natural media.

- The sludge: when the clarification process is finished, the residual sludge is stored in the settling lagoons or, in some cases, could be spread for agricultural practices. The next obvious question concerns the long-term behaviour of the polyacrylamide adsorbed on solid particles contained in the sludge.

The knowledge relative to the environmental behaviour of polyacrylamide and acrylamide (processing mechanisms and transfer, bioavaibility) are limited nowadays even at a rudimentary stage in the particular context of the use of flocculants. Until now, the major studies on acrylamide have dealt essentially with the formation of this toxic molecule in products from food-processing industry. The polyacrylamide was not much studied, essentially focusing on its degradation mechanism.

The risk associated with polyacrylamide use is then an important factor to understand. The scientific knowledge in this domain is too much limited to be able to assess the 
environmental impact of these products in this specific context. The low number of studies available on the environmental impact and ecological balances of flocculants use is mainly due to limits in developing efficient and reliable analytical techniques to follow these products in environmental media.

The topics covered in this special issue are diverse and they reflect the quality of the researches performed in the AquaPol research project in the sensitive field of spreading and degradation of polyacrylamide-based flocculants in sludge and industrial and natural waters. This project, funded by the French Research Agency (ANR, Agence Nationale de la Recherche), associated for more than 3 years scientists from various fields: metrology, process engineering, geochemistry, microbiology, eco-toxicology and hydrogeology. One of the main AquaPol purposes was to study the behaviour of acrylamide and polyacrylamide in process and natural waters and their impacts on the balance of aquatic ecosystems. The effort has been put on the particular case study of the mineralextracting industry which is one of the main flocculant users. The heart of the project was based upon the characterisation of the environmental fate of polyacrylamide and acrylamide in a French quarry which was used as a case study all along AquaPol project. This quarry uses polyacrylamide-based flocculants to clarify and to recycle their process waters. It was chosen with the help of the French aggregates producers association (UNPG, Union Nationale des Producteurs de Granulats) which was associated to the project partnership.

Prior to any in situ or ex situ testing, the first requirement of the project was to develop a sensitive analytical methodology for AMD analysis. A first procedure based on UPLC-MS/MS was developed for measuring acrylamide in natural waters (ground and surface water) at low concentrations both compatible with drinking water quality requirements and suitable for monitoring the fate of acrylamide in industrial process water. Besides this work, another analytical method was also developed using HPLC/MS/MS specifically for the monitoring of acrylamide adsorption testing. Both procedures were used in the project depending on the purpose of the analysis and on the desired quantification limit.

The next step of the project consisted in an in situ investigation of the dissemination of polyacrylamide and acrylamide in the quarry chosen as a case study. Acrylamide and polyacrylamide contents were quantified in several key points of the quarry washing process as well as in the surrounding aquifer; the microbiology, the biodiversity and the biological activity were also characterised using the same samples. At the same time, the hydrogeological characteristics of the study site were determined through pumping and tracer test field scale experiments, coupled with a mapping of the interface clogging.

In parallel biodegradation and mobility of both acrylamide and polyacrylamide in "environmental conditions" was studied through ex situ testing using information and samples obtained from the in situ study. Finally, a groundwater transport model was developed to estimate acrylamide spreading from the quarry washing process to the surrounding aquifers.

The results of these research works bring a better knowledge in the dissemination process of acrylamide and polyacrylamide in relation with the physico-chemical, microbiological and hydrological characteristics of the aquatic environments. They were completed by a global environmental assessment of the use of flocculants in the mineral-extracting industry.

The papers included in this special issue gather the main results of AquaPol project and those obtained in a previous research project led by the School of Mines of Ales (France). The authors have covered different topics from the development of analytical methods for acrylamide quantification to the comprehension and quantification of the mechanisms of acrylamide degradation and absorption. A mapping of acrylamide dissemination in different environments is also proposed as well as a modelling of acrylamide leakages from the process where PAM-based flocculants are injected towards the surrounding aquifers. The research work performed in AquaPol was supported by a thorough review of the literature devoted to the transfer and the degradation of PAM-based flocculants in hydrosystems which is also summarised in this special issue. It is expected that AquaPol development will give new insights into the fate of polyacrylamide and acrylamide in aquatic environments and bring to flocculant users and administrative authorities the scientific basis which can enable them to implement the appropriate measures to prevent potential environmental damages linked to the use of flocculants.

The guest editors would like to thank the ANR for its financial support which enabled to fulfil AquaPol objectives. The guest editors would like also to thank all authors contributing to this issue and the reviewers which provided constructive advice for the improvements of paper quality. They extend their sincere thanks to Springer for the opportunity offered to compile such a special issue, and would like to thank in particular the Editor-in-Chief of ESPR, Dr Philippe Garrigues and Editorial Assistant of the journal, Ms. Emmanuelle Pignard-Péguet, for their patient and unfailing support during this long process of elaboration of this issue.

\section{References}

European Parliament (1999) Directive 1999/45/EC concerning the approximation of the laws, regulations and administrative provisions of the Member States relating to the classification, packaging and labelling of dangerous preparations. Official Journal of the European Union L200/1. European Union, Brussels

European Parliament (2006) Regulation 1907/2006/EC concerning the Registration, Evaluation, Authorisation and Restriction of 
Chemicals (REACH). Official Journal of the European Union L396/1. European Union, Brussels

Molak V (1991) Acrylamide: a review of the literature in NIOH and NIOSH basis for an occupational health standard. US Department of Health and Human Services, 1991

Smith EA, Prues SL, Oehme FW (1996) Environmental degradation of polyacrylamides.1. Effects of artificial environmental conditions: temperature, light, and $\mathrm{pH}$. Ecotoxicol Environ Saf 35:121-135

Stephens SH (1991) Final report on the safety of polyacrylamide. J Am Coll Toxicol 10:193-202

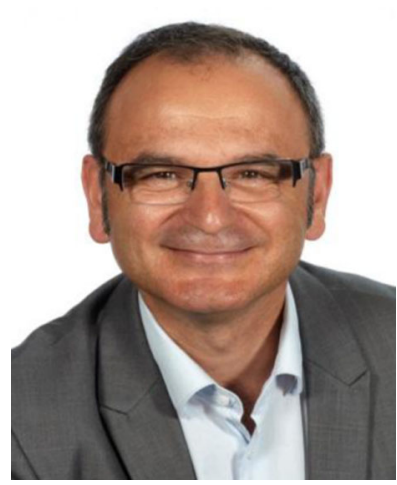

Jean Guzzo has been a Professor of Microbiology and Molecular Biology at the University of Burgundy since 1998. He earned his Ph.D. in Biology at Aix-Marseille University in 1987. He has specialised in bacteriology and has focused his research on bacterial adaptive responses to various harmful environments and on the characterisation of bacterial communities using molecular approaches. He has written or coauthored over 72 peer-reviewed articles, principally related to the understanding of the mechanisms involved in bacterial adaptation to physico-chemical stresses. He directed an academic INRA-University of Burgundy laboratory from 2001 to 2006. Since 1999, he has managed a Microbiology Master Degree in food and environmental sciences. In 2007, with Doctor Patrice Arbault, he funded Nexidia, a private service company, where he holds the Chief Scientific Officer position. Nexidia performs R\&D services in the field of industrial microbiology for agrofood, environment and pharmaceutical companies. Since July 2012, he has been the Vice President in charge of business partnerships for research and education at the University of Burgundy (Dijon, France).

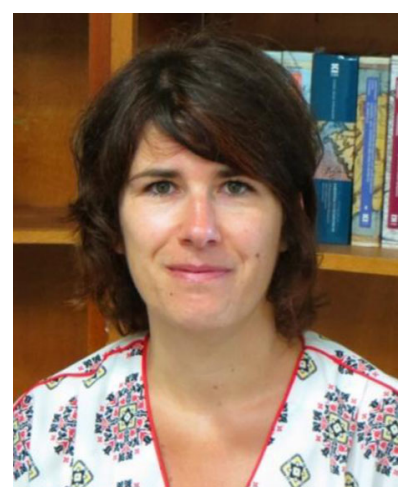

D r. A n n e - G wé n a ë ll e Guezennec received a Ph.D. degree in Materials Science and Engineering from the School of Mines of the University of Lorraine (Nancy, France) in 2004 She is currently working as a research scientist in the Department of Water, Environment \& Ecotechnologies of BRGM research center (Bureau de Recherche Géologique et Minière, the French geological survey). Her research works focus on the understanding of the interactions between aqueous solution and mineral phases applied to mineral processing (mainly hydrometallurgy) and wastewater treatment. She has also a large experience in the development of bacterially catalysed processes. 